\title{
Specifics of translating the realities of the Yakut national dress into Chinese
}

\author{
Tuiaara Ordakhova*, Anna Grigoreva \\ North-Eastern Federal University named after M.K. Ammosov, 677000, 58 Belinsky str., Yakutsk (Republic of Sakha), Russian \\ Federation
}

\begin{abstract}
At the moment, the difference in cultures, linguistic pictures of the world is practically not an obstacle to mutual understanding between peoples. The given problems are completely surmountable in translation. Words and expressions that have no analogues in any other language can exist in the linguistic pictures of the world of one nation. Such words are called realities, namely, words that reflect the peculiarities of culture, customs and rituals of various nationalities. The study of realities plays a crucial role in comprehending the culture of another nation. It is significant not to forget your culture, to know all its subtleties and differences in the age of globalization and the free study of the language and culture of various nationalities. Translation of national dress can cause difficulty for the translator and this study is being conducted with the aim of simplifying this type of translation.
\end{abstract}

\section{Introduction}

Intercultural communication is an important and relevant topic of our time. It is culture that can become a unifying space between people of diverse nationalities. We realize that it is impossible to lose the great cultural heritage that has evolved over thousands of years, and the diversity of the contemporary world is a condition for its further progress. The processes of intercultural exchange are the key to the civilization development. Language can be called the main component of culture. It is a repository and means of transmission between generations of cultural values and the most essential tool for cognizing reality.

\section{Materials and Methods}

The monograph "Folk costume of the Yakuts: a historical, ethnographic and art study" by S.I. Petrova and an illustrated album of B.F. Neustroev "Sakha oyuuta-bichige=Patterns and ornaments of Sakha/Mandar Uus" served as materials for research.

The term "realities" became widespread after the publications of S. Vlakhov and S. Florin "Untranslated in Translation" [1, 22]. S. Vlakhov and S. Florin understood "realities" as words and expressions indicating objects, phenomena, objects characteristic of everyday life, culture, social development of another nation, expressing national and temporal flavor. The given words and expressions do not have exact correspondences in another language, and therefore require a special approach when translating them $[2,45]$.

It is required to have certain knowledge about the reality that is depicted in the original text in order to correctly convey the meaning of realities, that is, to have some "background knowledge" of the translated language [3, p.320]. The correct comprehension of the text depends precisely on the knowledge of the culture and history of the nation on the language of which the text is written $[4,58]$. We have selected the following phraseological unit for an example: 黄袍加身 - we have put a yellow robe on him (means that proclaimed as an emperor); win a victory. When understanding the given phraseological unit, it is necessary to rely on a historical fact, namely: during the Later Zhou dynasty, Zhao Kuanyin raised a military mutiny in Chentsiao, after which he was put on a yellow robe, symbolizing the beginning of his reign as an emperor. Later, this phraseological unit began to be used to denote the success of the coup and the government success. It should be noted that only that part of the background knowledge matters that relates to phenomena specific to another culture, and is required for the translated text readers to assimilate its content $[5,165]$. It should be borne in mind that the clash of cultures occurs from the point of view of the interpreter's perception, his idea of a foreign culture, and its features $[3,320]$.

When translating realities, interpreters encounter several difficulties, namely: the lack of an equivalent in the target language, since the native speakers of the language into which the realities are translated do not have a concept denoted by reality. Besides, when translating reality, it is required to try to convey not only its meaning, but also the national and/or historical coloring. Similar ways of translating realities are given in the textbook by V.F. Shchichko "Theory and practice of translation" [6, 79-81], but in contrast to those given by V.S. Vinogradov, there are more ways:

1. Transcription;

2.Calquing;

Corresponding author: ordakhova@ mail.ru 
3. Descriptive translation - the use of a definition, a more detailed description of a word when translating it, from which it can be defined that this method is similar to the peripheral translation given by V.S. Vinogradov. The given method is the most often used among interpreters, as it is able to reveal the essence of an object or phenomenon being non-equivalent vocabulary [7, p.151].

4. Approximate translation is the use of a word (analogue) close to the original meaning when translating. The method of translation is similar to the hypo-hyperonymic translation by V.S. Vinogradov: both methods represent translation of reality using genusspecific substitution.

5. A functional analogue is a translation method when the translator, instead of the source language realities, uses the realities of the target language, which also has its national specifics and has much in common with the source language realities. The method is aimed at provoking a similar reaction from both the reader of the original and the reader of the translation. The positive side of the given translation method is that it is more understandable for the transfer recipient $[7,151]$.

For instance,

顾客是皇帝 - the customer is always right (literally: customer is the emperor)

6. The last method of translating reality is a combined method, which includes the above translation methods grouped together:

- Transcription and calque

For instance, 诺贝尔奖金 - Nobel Prize (诺贝尔 nuòbèi’ěr - Nobel, 奖金 - Prize);

- Transcription and explanation

For instance,

气功 - breathing exercises "Chikung";

- Calque and explanation

For instance,

五岳 - five sacred peaks of China: Oriental - Taishan 泰 山; Western - Huashan 华山; Southern - Hengshan 衡山; Northern - Hengshan 恒山; Central - Sungshan 嵩山.

The reality content and its national coloring can be more fully conveyed with combined translation methods.

There are cases when translators overestimate the background knowledge of the reader and do not explain the reality meaning. Some translators expect that readers, being not familiar with the reality, will inquire about the meaning of the unfamiliar reality in dictionaries. However, according to S. Vlakhov and S. Florin, an ordinary reader who reads books for pleasure will not rummage through dictionaries.

\section{Results and Discussion}

The national dress of the Yakuts combines not only the cultural traditions and everyday life of the people, but also their adaptability in the harsh climatic conditions of the North. It has undergone various transformations under the influence of time and cultures of diverse peoples; nevertheless, it retains its artistic traditions.
We selected 40 types of women's national clothing for the research by means of continuous sampling from the monograph by S.I. Petrova, Z.M. Zabolotskaya "The folk costume of the Yakuts: a historical, ethnographic and art study" and an illustrated album by B.F. Neustroev "Sakha oyuuta-bichige=Patterns and ornaments of Sakha/Mandar Uus", classified the chosen elements of clothing by purpose and application. We consider the first group of realities "Headgear" in the paper.

\section{Women's headgear:}

1. Muostaakh bergehe - a fur bonnet with horns. Horns were sewn from the tip of the animal's tail with valuable fur and decorated with beads. This hat symbolized the generosity and wealth of its owner. Calquing. Muostaakh bergehe is translated into Russian as "a hat with horns", and into Chinese - 角 帽子(角 - horns, 帽子 - hat). When questioning the preferred translation of this heading among native Chinese speakers, the calquing method scored only $10.77 \%$, which took the third and last place.

Descriptive translation. 萨哈族传统有尾角的表皮 帽 - yakut traditional fur hat with tail horns (萨哈族 - Sakha people, 传统 - tradition, 尾角 - tail horn, 表 皮帽 - fur hat). It should be emphasized that when translating our nationality, we used the translation option of 萨哈族 (Sakha), but not 雅库特族 (the Yakuts), for the reason that the Yakuts name themselves as Sakha and therefore, in our opinion, the first option is more preferable. If we talk about the survey result, then the Chinese speakers chose the given method as the preferred translation for this hat, which not only describes the hat, but also conveys its national coloring. It took $67.69 \%$ of the votes, which no doubt puts the given variant in the first place.

Functional analogue. 狍头皮帽 - roe deer scalp hat (狍 - roe deer, 头皮 - skin on the head, scalp, 帽 hat), is the traditional fur hat of the Orochon people (a national minority in Mongolia and China) [38]. The hat also has horns and looks like our muostaakh bergehe. Probably, that is why it took the second place for the best translation, receiving $21.54 \%$ of the vote.

2. Muostaakh nuogaydaakh bergehe - women's wedding hat with horns and a pommel with a feather sultan.

Calquing. If we have figured out that muostaakh bergehe is a "hat with horns", and then the word nuоқaydaakh (nuobai) is still unfamiliar to us. So nuobai is a feather or fur attached to a hat. As a result of calque muostaakh nuoқaydaah bergehe into Chinese is: 角羽帽子 - hat with horns and feather (角 - horns, 羽 - feather, 帽子 - hat). According to the survey, calque received $28.57 \%$ of the votes, thus taking the second place among the translation options for muоstaakh пио5аydaah bergehe.

Descriptive translation. Hat image as 萨哈族传统 女的有角和羽毛的结婚帽 - Yakut traditional women's wedding hat with horns and feather (有 have, 角 - horns, 羽毛 - feathers and wool, 结婚 - 
wedding, 帽 - hat), brought $54.29 \%$ of the votes, making this description the most successful translation.

Combined method: calque and explanation. 萨哈 族传统女的角羽帽子 - Yakut traditional women's hat with horns and feather. Changes occurred in adding the calque 角羽帽子 instead of the second part of the descriptive translation 有角和羽毛的结婚 帽. The percentage of those who voted for this translation is only $17.14 \%$, demonstrating the worst result.

3. Diabaka is a women's fur hat, decorated on the front with a wide fringe of wolverine, beaver, and sable fur, on the back - with a lynx, with a pommel of red and black cloth, richly decorated with embroidery from colored and gold threads or a pattern of beads and kinglets. The diabaka hat is a mandatory attribute in rituals related to childbirth.

Transcription. We have transcribed the diabaka using the Xinhua "Large dictionary of foreign personal names translation", and thus the hat in Chinese sounds like 达巴卡(dábākă). As a survey result, the transcription of the hat took the third place out of five, gaining $15.38 \%$ of the total percentage.

Calquing. Diabaka is a fur hat. Accordingly, the translation into Chinese is presented as follows: 皮帽 子(fur hat). The given calque was not endorsed by native Chinese speakers as the best translation for diabaka, ranking the last place in the survey with $4.62 \%$.

Descriptive translation. The diabaka hat description turned out as follows: 萨哈族传统的女 的头饰, 前后用皮草缝制, 上部饰有花纹织物 Yakut traditional women's headgear, stitched with fur on the front and back, and decorated with patterned fabric on top (头饰 - headgear, 前后 - on the front and back, 用 - use, 皮草 - fur, 缝制 - sew, 上部 - top, 饰有 - decorate (with), 花纹 - pattern, patterned, 织物 - fabric). The survey shows that the given descriptive translation is the most successful among the rest ones, gaining more than half of the total $-53.89 \%$.

Combined method: transcription and calque. 皮帽 子"达巴卡" - fur hat “diabaka”. The abovementioned combined translation scored $9.23 \%$, thus ranking fourth out of five. Combined method: transcription and explanation: 萨哈族传统女式皮草 帽"达巴卡" - Yakut traditional women's fur hat "diabaka." Following on from the results, the given translation received $16.92 \%$ of the votes, which put it in second place, slightly ahead of the transcriptional translation method.

4. Uraa bergehe - an ancient pointed hat of the bride, shaped like a birch bark yurt. The feathers of a certain bird were strengthened around a small hole on the crown, which was the spirit of the ancestral deity of the bride (thus, the ancestral affiliation of the owner could be determined). The bunches of feathers had a magical-protective value; they were also considered a means of inducing fertility.

Calquing. The word "uraa" in Russian means a chimney, accordingly, this item received the following translation at calque: 烟图形帽子 - hat in the form of a chimney (烟图 - chimney, 形 - form, view, 帽子 - hat). Probably because the appearance of the chimney, from which the hat took its name (meaning the Yakut fire chamber), is not clear, so it has caused difficulty in perception, since the given calque takes the last place in the poll, gaining $3.08 \%$.

Descriptive translation. Uraa bergehe was described as 萨哈族传统尖头新娘礼帽, 上面饰有 羽毛 - Yakut traditional pointed wedding hat decorated with feathers on top (尖头 - pointed, 新娘 - bride, 礼帽 - ceremonial headgear, 上面 - top, 饰 有 - decorate (with), 羽毛 - feathers and wool). The mentioned descriptive translation was ranked second as the best translation of national clothing, gaining 26.15\%. Functional analogue. We found outwardly resembling our hat on Kazakh women. Kazakh people live not only in Kazakhstan, but also in other countries, including China. Their hat is called "saukele" and has a transcriptional translation in Chinese 沙吾克烈 (shāwúkèliè). Despite the external similarity, the functional analogue did not receive approval in the survey, gaining only $7.69 \%$.

Combined method: transcription and calque. We have added a transcription of "uraa" in addition to the calque above 乌拉, in the issue we obtain: 烟图形帽 子"乌拉" - chimney-shaped "uraa" hat. Survey outcomes show $7.69 \%$, the identical result with the above functional analogue.

Combined method: transcription and explanation. The transcription 乌拉 has also been added to the descriptive translation: 萨哈族传统尖头新娘礼帽" 乌拉", 上面饰有羽毛 - Yakut traditional pointed wedding hat "uraa" decorated with feathers on top. The percentage of those who has voted for this translation option is $55.38 \%$, thereby gaining the largest number of votes.

5. Chomooluska - cheek-chin and forehead fur set for women. Transcription. Chomooluska in Chinese is 乔莫卢斯卡 (qiáomòlúsīkă). The percentage of votes for this translation is only $20 \%$. Descriptive translation. 萨哈族传统女的帽子下的皮毛套件, 覆 盖额头, 脸项和下巴 - Yakut traditional women's fur set under the hat, covering the forehead, cheeks and chin (皮毛 - fur, 套件 - set, 覆盖 - cover, 额头 - forehead, 脸颊 - cheek, 下巴 - chin). The percentage of those who has voted for this translation is $34.29 \%$.

Combined method: transcription and explanation.

Combining the above two translations, we obtain: 萨哈族传统女的帽子下的皮毛套件"乔莫卢斯卡 ", 覆盖额头, 脸颖和下巴 - Yakut traditional women's fur set under the hat "chomooluska", covering the forehead, cheeks and chin. The given combined translation has been approved by $45.71 \%$ 
of voters, thus becoming the preferred translation option.

\section{Men's headgear:}

1. Tapylai bergehe is a winter hat, sewn according to the shape of the head and without a visor, trimmed with fur in the front and back, covers the cheeks up to the chin.

Transcription. The phonetic sound of tapylai is conveyed using the following characters due to the official transliteration standard published by Xinhua: 塔佩莱(tăpèilái). The percentage of votes for the first translation of tapylai bergehe is only $11.43 \%$.

Descriptive translation. For the translation, we have distinguished the shape of the hat and the attachment to a certain nation - the Sakha people in our case: 萨哈族传统男的头形冬帽 - Yakut traditional men's winter hat in the shape of a head (男的 - men, 头 - head, 形 - shape, view 冬 - winter, 帽 - hat). More than half of the surveyed Chinese voted in favor of the given tapylai translation with a $54.29 \%$ of votes, making it the preferred Chinese translation of the tapylai.

Functional analogue. We have found a hat that looks like tapylai among the Mongols: their hat is called 三耳帽、四耳帽 - a hat with three, four ears (三 - three, 四 - four, 耳 - ear, ears, 帽 - hat) [49]. The hat is worn like tapylai in winter. The percentage of votes according to the survey outcomes is only $17.14 \%$.

Combined method: transcription and explanation. We have combined the two above translations, conveying not only the hat's description, but also its name, which is phonetically close to the original: 萨 哈族传统男的头形冬帽"塔佩莱" - Yakut traditional men's winter hat "tapylai" in the shape of a head. The survey outcomes show a similar result with a functional analogue: the given translation has only $17.14 \%$ of the votes.

2. Chompoy bergehe - cone-shaped high Yakut hat.

Transcription. An approximate translation of the chompoy hat to the original phonetic form in Chinese is 琼波 (qióngbō). The given transcription has received a small number of votes, like the previous transcriptional translations: the percentage of voters is $11.43 \%$.

Calquing. "Chompoy" is represented as a coneshaped hat in the E.K. Pekarsky, accordingly, the calque in Chinese is 雉形帽 (雉形 - cone-shaped, 帽 - hat). The literal translation of the hat name is appreciated only by $17.14 \%$ of the survey participants, which shows the average result among other variants of the chompoy hat translation.

Descriptive translation. We have marked again the hat's shape in the given type of translation, since this is exactly what makes the chompoy stand out from the rest of the hats: 萨哈族传统男的雉形高帽 子 - Yakut traditional men's cone-shaped high hat (雉形 - cone-shaped, 高 - high, 帽子 - hat). The translation received $25.71 \%$ of the votes, which is a fairly high and good result. Nevertheless, the given variant lagged behind the combined translation of transcription and explanation by a small margin.

Combined method: transcription and calque. The next type of combined translation resulted from the combination of calquing and transcriptional translations: 雉形帽 "琼波 " - cone-shaped "chompoy" hat. This translation conveys not only the hat's shape, but also its original name, thus preserving the national coloring. However, the percentage of votes for this translation is only $11.43 \%$, identical to the transcriptional translation.

Combined method: transcription and explanation. 萨哈族传统男式雉形高顶帽"琼波" - Yakut traditional men's cone-shaped high "chompoy" hat. As previously mentioned, this translation got the largest number of votes in the survey: the percentage of votes was $31.43 \%$.

Combined method: calque and explanation. There is the latest translation version of the chompoy hat, which we have translated as 萨哈族传统男的雉形帽 (Yakut traditional men's cone-shaped hat), and it has received the least number of votes: only $2.86 \%$.

3. Habakh bergehe - a summer hat made of a cut bladder of an animal with a rim of reindeer rovduga or fabric.

Calquing. "Habakh" means bladder. The presented calque of the hat's name in Chinese is as follows: 膀胱帽 (膀胱 - bladder, 帽 - hat). Probably, the majority of Chinese speakers have difficulties in comprehension of the hat's name, because the percentage of votes is only $11.43 \%$.

Descriptive translation. The following translation method explains in more detail the material for making the hat: 萨哈族传统动物膀胱制成的夏季帽 子 - Yakut traditional men's summer hat made from the animal bladder (动物 - animal, 膀胱 - bladder, 制成 - make, 夏季 - summer). The translation was appreciated by $42.86 \%$ of respondents, making it the best translation.

Approximate translation. We have also added a translation replaced by a generic term to our survey: 帽子. The translation received only $11.43 \%$ of the votes.

Combined method: calque and explanation. In addition to explaining the material for making the hat, there is also the hat's name, which has undergone a calquing translation so that Chinese speakers could guess where the name of the cap comes from: 萨哈 族传统动物膀胱制成的膀胱帽. The given translation has received $34.29 \%$ of the votes, which is a good result, lagging behind the descriptive translation by about $8 \%$.

\section{Conclusion}

Realities belong to a specific nation, country and convey the national coloring. Realities are not created artificially, but from the speech of native speakers. The reality is not equivalent, but one cannot list all the non-equivalent 
words to the realities if they do not belong to a certain nation.

It is required to try to convey both the meaning and the national or historical coloring when translating realities. There is no universal way of conveying reality, so we should find a special approach to translating each reality, relying on background knowledge, context, reality nature, and language.

In the course of the study, it turned out that native Chinese speakers preferred descriptive and combined methods of translating the realities of the headgears of the Yakut national dress.

\section{References}

1. V.N. Egoshin, The translation issue from Russian into English (based on the stories of A.P. Chekhov), Linguistics: from theory to practice: collection of articles, 41-49 (2015)

2. S. Vlahov, S. Florin, Untranslatable in translation, 342 (International relationships, Moscow, 1980)

3. N.K. Garbovskij, Translation theory: Textbook, 544 (Lomonosov Moscow State University, Moscow, 2007)

4. V.S. Vinogradov, Introduction to Translation Studies (general and lexical issues), 224 (Institute of General Secondary Education of the Russian Academy of Education, Moscow, 2001)

5. A.V. Fedorov, Fundamentals of general translation theory (linguistic issues): For institutes and faculties of foreign languages. Study guide, 416 (Saint Petersburg State University, Saint Petersburg; Philology Three, Moscow, 2002)

6. V.F. Shchichko, Theory and practice of translation, 224 (Vostochnaya Kniga, Moscow, 2017)

7. L.K. Latyshev, Translation technology: Study guide for the preparation of translators (from German), 280 (Moscow, NVI-THESAURUS, 2000) 